\title{
Scales to measure motivation among community health workers, and trust and empowerment among their clients: A guide
}

Frontline Health Project

Follow this and additional works at: https://knowledgecommons.popcouncil.org/departments_sbsr-rh

Part of the Community Health Commons, Health Services Research Commons, and the International Public Health Commons

How does access to this work benefit you? Let us know!

\section{Recommended Citation}

Frontline Health Project. 2020. "Scales to measure motivation among community health workers, and trust and empowerment among their clients: A guide." Washington, DC: Population Council. 


\section{SCALES TO MEASURE MOTIVATION AMONG COMMUNITY HEALTH WORKERS, AND TRUST AND EMPOWERMENT AMONG THEIR CLIENTS: A GUIDE}

\section{BACKGROUND}

This brief presents five multi-item scales to measure motivation among community health workers (CHWs), as well as clients' trust in CHWs and empowerment within community health systems. The scales were developed as part of the Frontline Health project, which seeks a standardized, validated, and pragmatic set of indicators to measure $\mathrm{CHW}$ performance within the context of community health systems. CHWs are frontline health workers with up to six months of initial training, who are often the primary link to essential health services for millions of people worldwide, particularly those living in remote or rural areas (1).

The Multi-dimensional Motivation (MM) scale is intended for use with $\mathrm{CHWs}$ and includes four sub-dimensions: Quality of supervision; Feeling valued and capacitated in your work; Peer respect and support; and Compensation and workload. The MM scale applies a two-step approach of assessing key dimensions of satisfaction, then weighting each by its importance.

Four other scales, intended for use with community members/clients of $\mathrm{CHWs}$, include:

Trust in CHWs (with two sub-dimensions: Healthcare competence and Respectful communication) Trust in CHWs is a client's perception of how reliable and responsive CHWs are and also proxies how well a health system upholds its social contract with the community.

Client Empowerment in Community Health Systems (CECHS) (with three sub-dimensions: Personal agency around health; Agency in sharing health information with others; and

\section{WHAT IS A SCALE?}

Scales are often used in the social and behavioral sciences. A scale is a collection of survey items combined into a composite score and intended to reveal levels of a "latent" variable i.e., one that is not directly measurable or observable (for example, CHW motivation). Responses to the items share a common cause, which is the theoretical variable of interest (2).

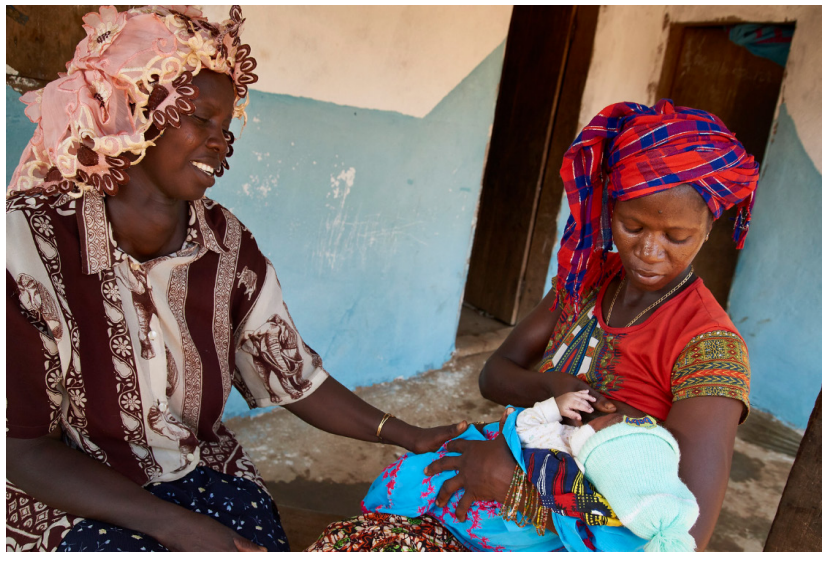

A CHW counsels a breastfeeding mother. Photo credit: UNICEF, 2017

Engagement with community health systems). The CECHS scale measures client empowerment at personal, interpersonal, and community levels. The full scale can be used to assess multiple dimensions of empowerment, or sub-scales can be implemented individually as users see fit.

Influence of CHWs on Empowerment: This scale directly and concisely assesses clients' perceived effect of CHWs on five health-related empowerment behaviors, which align with the three sub-dimensions of the CE-CHS Scale.

Civic Engagement: This scale can be used to assess valuable non-health outcomes of community health systems and $\mathrm{CHW}$ performance.

These scales can be used across a variety of country settings and health areas. Each scale was developed through a consultative process and drew on items from other existing scales whenever possible, and was administered in crosssectional surveys from 2019 to early 2020. The Multidimensional Motivation scale was included in surveys with CHWs in Bangladesh $(n=152)$ and Mali $(n=76)$ from Nov. 2019Jan. 2020. The community-centric scales were included in surveys with clients of CHWs in Bangladesh $(n=1,384)$, Haiti $(n=616)$, and Kenya $(n=306)$.

Evaluating performance of the scales involved exploratory and confirmatory factor analysis, as well as assessment of reliability and convergent validity (i.e., association with other theoretically related variables). 


\section{COMMUNITY HEALTH SYSTEMS PERFORMANCE MEASUREMENT FRAMEWORK}

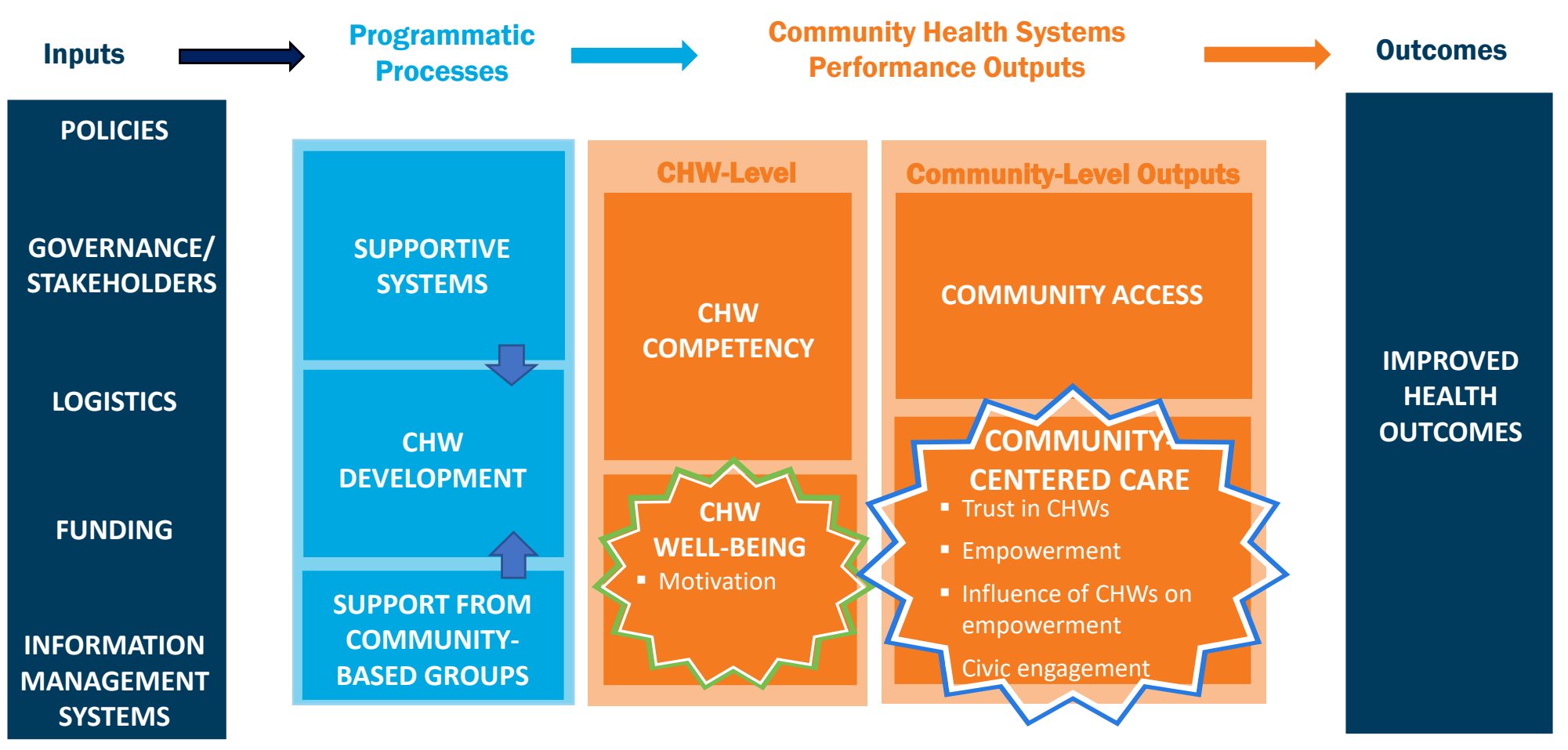

Key:

Scales for use with $\mathrm{CHWs}$

Scales for use with community members/clients of $\mathrm{CHWs}$

Each scale (and sub-dimension) demonstrated excellent structural validity, reliability, and convergent validity. More detailed information about scale performance is available in a series of published manuscripts $(3,4,5)$.

The scales presented in this brief assess specific latent (not directly measurable) elements within the Community Health Worker Performance Measurement Framework (1). A simplified version of this framework with emphasis around the scales is shown above. The scales are intended to be used in combination with other indicators in the framework, collected as part of surveys, program records, observations, and routine data monitoring for quality improvement and accountability in community health. Implementing these scales can contribute to measuring progress towards recommendations outlined in the World Health Organization's (WHO) CHW Guidelines, the Community Health Roadmap, the Community Health Worker Assessment and Improvement Matrix (CHW AIM) toolkit, and the Minimum Quality Standards and Indicators for Community Engagement.

\section{REFERENCES}

1. Agarwal S, Sripad P, Johnson C, Kirk K, Bellows B, Ana J, . . Casseus A. (2019). A conceptual framework for measuring community health workforce performance within primary health care systems. Human resources for health, 17(1), 86.

2. DeVellis, RF (2016). Scale development: Theory and applications (Vol. 26): Sage publications.

3. Gottert A, McClair T, Hossain S, Dakouo SP, Abuya T, Kirk K, Bellows, B, Agarwal S, Kennedy S, Warren C, Sripad P. Development and validation of a multi-dimensional scale to assess community health worker motivation. Journal of Global Health; accepted.

4. McClair T, Sripad P, Casseus A, Hossain S, Abuya T, Gottert A. The Client Empowerment in Community Health Systems Scale: Development and validation in three countries. Journal of Global Health; accepted.

5. Sripad P, McClair T, Casseus A, Hossain S, Abuya A, Gottert A. Measuring client trust in community health workers: $a$ multi-country validation study. Journal of Global Health; accepted. 
Satisfaction items: How would you rate satisfaction with the following aspects of your work?

Response options: Very dissatisfied [-2], dissatisfied [-1], satisfied [1], very satisfied [2]

Quality of supervision

1. Respect received from supervisors on performing well

2. Support your direct supervisor gives you in your work

3. Fairness with which your performance is measured

4. Coordination between your supervisor, community health leaders, and stakeholders

5. Ease with which you can communicate with your supervisors

6. Appreciation shown by your supervisor for your work Feeling valued and capacitated in your work

7. Respect received from community for doing this work

8. Opportunities to update your health knowledge related to your work

9. Autonomy to make decisions while working

10. Opportunities to contribute your ideas to improve services

11. Consideration of your views and ideas by community health leaders and stakeholders

12. Availability of drugs, supplies, and equipment for your work

Peer respect and support

13. Support your coworkers (CHWs) give you in your work

14. Attitude of colleagues (in our case, $\mathrm{CHWs} /$ peers)

15. Respect received from other $\mathrm{CHWs}$ on performing well

16. Cooperation among $\mathrm{CHWs}$

17. Mutual trust $\mathrm{CHWs}$ have for each other

Compensation and workload

18. Amount of total financial incentives you receive

19. Timeliness in receiving financial incentives

20. Additional payment for your work

21. Number of hours you work in a typical day

22. Long term job security

Importance items: How important to you are the following aspects of your work? (Read each statement out in full, including parentheses)

Response options: Not very important [1], important [2], very important [3]

1. Quality of supervision (that is, your supervisor(s) actively support and value your work, and treat you respectfully and fairly)

2. Feeling valued and capacitated in your work (that is, feeling your work is respected by the community, you have the tools and training you need)

3. Peer respect and support (that is, support, trust and cooperation among your peers at work)

4. Compensation and workload (that is, enough and timeliness of compensation, including in relation to your workload)

Generating final motivation scores:

1. Generate the mean* of the set of satisfaction items for each sub-dimension.

2. Multiply each of these four mean scores (ranging from -2 to +2 ) by its importance (scored 1,2 or 3 ). Possible values of the resulting Motivation scale sub-dimensions will range from -6 to +6 .

3. To generate the final score for the full Motivation scale, sum the four sub-dimension scores. Possible values will range from -24 to +24 .

* Preferable to take the mean of all non-missing values so as not to drop cases. 


\section{TRUST IN CHWS SCALE1}

Think about all the interactions you've had with $\mathrm{CHWs}$ in the last six months or so.

Response options: Never [1], some of the time [2], most of the time [3], or all of the time [4] Health care competence

1. How often have you felt the $\mathrm{CHW}$ was telling you everything you needed to know about your health-related problems?

2. How often have you felt the $\mathrm{CHW}$ knew as much as s/he should about a health topic?

3. How often has the $\mathrm{CHW}$ taken enough time with you during visits?

4. How often has the CHW kept what you discussed confidential/private from others in your community?

5. In your opinion, how often has the $\mathrm{CHW}$ been committed to providing the best care possible?

Respectful communication

6. How often has the $\mathrm{CHW}$ been an excellent listener?

7. How often have you felt better (emotionally) after seeing/talking to the CHW?

8. How often has the $\mathrm{CHW}$ treated you with respect?

9. How often has the $\mathrm{CHW}$ had your best interest at heart?

10. How often has the $\mathrm{CHW}$ made you feel that you were worthy of his/her time and effort?

Generating trust scores:

Generate mean sub-scale and full-scale scores by taking the mean of non-missing items for a final range of 1 to 4 .

\section{CLIENT EMPOWERMENT IN COMMUNITY HEALTH SYSTEMS} (CE-CHS) SCALE ${ }^{2}$

Now I will read a series of statements. Please let me know how much you agree or disagree with each of these statements.

Response options: Strongly disagree [1], disagree [2], agree [3], or strongly agree [4]

Personal agency around health

1. I feel in control of my health.

2. I know what to do when I have a health problem.

3. I know what to do when there is a health problem in my family.

4. I believe that I can participate in finding a solution to my health problem.

5. When a health problem arises in my family, I am able to help find a solution.

6. When I have a health problem, I advocate for myself to make sure I get good care.

7. When there is a health problem in my family, I advocate for them to get good care.

Agency in sharing information with others

8. I feel confident sharing about my health experiences with my family/friends.

9. I feel confident sharing health information with my family/friends.

10. I feel confident sharing health information with others in my community in one-on-one conversations.

11. I feel confident sharing health information with others in my community when in group/public settings. Engagement with community health systems

12. There are ways for me to participate in sharing my concerns/giving feedback to providers/managers at health facilities.

13. There are ways for me to participate in sharing my concerns/giving feedback to local leaders in my community.

14. Most facility providers/managers would listen to any concerns I raise.

15. Most local leaders in my community would listen to any concerns I raise.

16. I can participate in making decisions that can improve health in my community.

1. Scale from: Sripad P, McClair T, Casseus A, Hossain S, Abuya A, Gottert A. Measuring client trust in community health workers: a multi-country validation study. Journal of Global Health; accepted. 
INFLUENCE OF CHWS ON EMPOWERMENT SCALE

Now I will read a series of statements. Please let me know how much you agree or disagree with each of these statements.

Response options: Strongly disagree [1], disagree [2], agree [3], or strongly agree [4]

1. I can better make decisions about my health and my children's health because of my interactions with CHWs.

2. I can better share health information with others because of my interactions with $\mathrm{CHWs}$.

3. I can better get the care I need from my clinic because of my interactions with CHWs.

4. I can better improve my clinic and/or the health system because of my interactions with CHWs.

5. I can better contribute to my community because of my interactions with $\mathrm{CHWs}$.

Generating scores

Generate mean scale score by taking the mean of non-missing items for a final range of 1 to 4 .

\section{CIVIC ENGAGEMENT SCALE}

Now I will read a series of statements. Please let me know how much you agree or disagree with each of these statements.

Response options: Strongly disagree [1], disagree [2], agree [3], or strongly agree [4]

1. I like to work on solving a problem in my community rather than waiting for someone else to address it.

2. I understand what's going on in my community.

3. I understand the important social issues that affect my community.

4. I understand the important government/policy issues that affect my community.

5. I understand the important environmental issues that affect my community.

6. I can participate in making decisions for my community.

7. There are plenty of ways I can participate in making decisions for my community.

Generating scores

Generate mean scale score by taking the mean of non-missing items for a final range of 1 to 4 .

Scales on this page from: McClair T, Sripad P, Casseus A, Hossain S, Abuya T, Gottert A. The Client Empowerment in Community Health Systems Scale: Development and validation in three countries. Journal of Global Health; accepted.

Suggested citation: Frontline Health Project. November 2020. Scales to Measure Motivation among Community Health Workers, and Trust and Empowerment among their Clients: A Guide. Washington,

D.C.: Population Council.

\section{FOR MORE INFORMATION OR QUESTIONS ABOUT HOW TO USE THE SCALES, CONTACT:}

Ann Gottert, Associate, Population Council

agottert@popcouncil.org

Pooja Sripad, Associate, Population Council,

psripad@popcouncil.org

Tracy McClair, Staff Associate, Population Council

tmcclair@popcouncil.org

The Frontline Health: Harmonizing Metrics, Advancing Evidence, Accelerating Policy project seeks to advance community health systems metrics, monitoring and learning to improve the efficiency and performance of community health worker programs. www.popcouncil.org/research/frontline-health-harmonizing-metrics-advancing-evidence 